\title{
SENTIMENTOS EXPERIMENTADOS POR EQUIPES DE ENFERMAGEM ACERCA DOS ERROS DE MEDICAÇÃO
}

\author{
Cibele Leite Siqueira ${ }^{1}$, Kemilys Marine Ferreira ${ }^{2}$, Thamyres Caproni de Souza ${ }^{3}$, Liliane Bauer Feldman ${ }^{4}$
}

\begin{abstract}
RESUMO: O objetivo foi conhecer os sentimentos experimentados por equipes de enfermagem acerca dos erros de medicação e quais estratégias utilizadas pelos profissionais para preveni-los. O estudo foi exploratório qualitativo, realizado num hospital em Minas Gerais, Brasil, em 2014. Participaram onze profissionais de enfermagem que responderam entrevista por meio do instrumento semiestruturado. No resultado da análise temática emergiram quatro categorias: 1) deficiência na conceituação do erro, 2) sentimentos negativos associados ao erro, 3) condutas adotadas perante erro de medicação, e 4) estratégias de prevenção contra os erros de medicação. Constatou-se fragilidade na conceituação do erro; a percepção do sentimento de medo não relacionado à punição; a presença das competências, de responsabilidade e de comunicação usadas frente ao erro e a aplicação de barreiras e estratégias preconizadas para prevenção do erro. Sugere-se a implantação da sensibilização contínua focada em segurança como estratégia para alcançar aprendizado, disseminar as condutas assertivas dos profissionais e promover ações para aliviar os sentimentos dos envolvidos.
\end{abstract}

DESCRITORES: Emoções; Erros de medicação; Gerenciamento de segurança; Cuidados de Enfermagem; Segurança do paciente.

\section{FEELINGS EXPERIENCED BY NURSING TEAMS AFTER THE OCCURRENCE OF MEDICATION ERRORS}

ABSTRACT: The present study aimed to identify the feelings experienced by nursing teams regarding medication errors and the strategies used to prevent them. Exploratory and descriptive study carried out in a hospital in Minas Gerais, Brazil,in2014. Data was collected through semi-structured interviews Semi-structured interviews were conducted with the eleven participants. Four categories emerged from thematic analysis: 1) inadequate conceptualization of error, 2) negative feelings associated to the error, 3 ) Nurses' responses to medication errors;and 4) strategies for preventing medication errors. Inability to define error was observed; perception of a feeling of fear not related to punishment; the existence of skills/competences, responsibility and communication in response to error, and the use of barriers and strategies recommended for the prevention of errors. The implementation of continuous awareness of safety as a strategy to improve learning, disseminate assertive behaviors of the professionals and promote actions to mitigate the feelings of those involved in medication errors is suggested.

DESCRIPTORS: Emotions; Medication errors; Safety management; Nursing care; Patient safety.

\section{SENTIMIENTOS EXPERIMENTADOS POR EQUIPOS DE ENFERMERÍA ACERCA DE LOS ERRORES DE MEDICACIÓN}

RESUMEN: Fue objetivo del estudio conocer los sentimientos experimentados por equipos de enfermería acerca de los errores de medicación y cuales son las estrategias utilizadas por los profesionales para prevenirlos. Es un estudio exploratorio cualitativo, realizado en un hospital en Minas Gerais, Brasil, en 2014. Participaron 11 profesionales de enfermería que contestaron entrevista por medio de instrumento semiestructurado. Resultaron del análisis temático cuatro categorías: 1) deficiencia en la conceptuación del error, 2) sentimientos negativos asociados al error, 3) conductas adoptadas delante del error de medicación, y 4) estrategias de prevención contra los errores de medicación. Se constató fragilidad en la conceptuación del error; la percepción del sentimiento de miedo no relacionado a la punición; la presencia de las competencias, de responsabilidad y de comunicación usadas delante del error y la aplicación de barreras y estrategias preconizadas para prevención del error. Se sugiere la implantación de la sensibilización continua enfocada en seguridad como estrategia para alcanzar aprendizado, diseminar las conductas asertivas de los profesionales y promover acciones para aliviar los sentimientos de los involucrados.

DESCRIPTORES: Emociones; Errores de medicación; Gestión de seguridad; Cuidados de Enfermería; Seguridad del paciente.

${ }^{1}$ Enfermeira. Doutora em Ciências da Saúde. Docente da Pontifícia Universidade Católica de Minas Gerais. Poços de Caldas, MG, Brasil.

${ }^{2}$ Enfermeira. Especialista em Enfermagem do Trabalho. Enfermeira Supervisora da Unidade de Terapia Intensiva Geral do Hospital Santa Lúcia - Hospital do Coração. Poços de Caldas, MG, Brasil.

${ }^{3}$ Enfermeira. Pontifícia Universidade Católica de Minas Gerais. Enfermeira do Hospital Santa Lúcia - Hospital do Coração. Poços de Caldas, MG, Brasil.

${ }^{4}$ Enfermeira. Doutora em Ciências. Docente do Centro Universitário São Camilo Pompeia. São Paulo, SP, Brasil.

Autor Correspondente:

Recebido: $24 / 02 / 2016$

Liliane Bauer Feldman

Finalizado: 25/072016

Centro Universitário São Camilo Pompeia

R. Traipu, 704 - 01235-000 - São Paulo, SP, Brasil

E-mail: lilianedoutora@gmail.com 


\section{INTRODUÇÃO}

A enfermagem é uma profissão relevante na medida em que cuida do paciente e prima pela qualidade em tempo integral. Entretanto, devido a incidentes causados por diversos motivos, como falhas organizacionais, processos assistenciais equivocados, sobrecarga de tarefas, entre outros, acaba aparecendo na mídia envolvida em situações emblemáticas ${ }^{(1)}$.

O erro de medicação é um evento adverso que prejudica o paciente, causado pela indução ou uso inadequado do medicamento e é passível de prevenção. Pode estar relacionado à prescrição, dispensação, preparo, aplicação e ou qualquer fase do processo em que profissionais médicos e farmacêuticos também atuam ${ }^{(2)}$.

O evento adverso dispara variadas implicações para os pacientes, usuários, profissionais, instituições e ou meio ambiente. Pode causar dano pessoal, material, moral e de prestígio ao serviço ${ }^{(3)}$; aumentar o tempo de internação e elevar a exposição aos riscos ${ }^{(4)}$. Os gastos financeiros se potencializam, além de ocorrer queda nos indicadores de qualidade e segurança assistencial(4-5). Em relação aos profissionais envolvidos, podem ocorrer punições e demissões, afetar a competência, desempenho do trabalhador, abalar o equilíbrio emocional e surgir sentimentos de incapacidade, incompreensão e infelicidade oriundos do evento ${ }^{(3,5)}$.

Preocupando-se em prevenir e reduzir estas incidências, o Ministério da Saúde criou Portaria n 529 em 1/4/2013 - Programa Nacional de Segurança do Paciente (PNSP), que objetiva minimizar os eventos adversos e melhorar a qualificação do cuidado em todos estabelecimentos de saúde do Brasil( ${ }^{(6)}$.

Para isso, segundo o PNSP, é preciso que a liderança adote uma política de segurança institucional e forneça recursos humanos capacitados concedendo-Ihes autonomia ${ }^{(6)}$. Deve-se elaborar o plano de ação para gerir os riscos, implantar barreiras preventivas nos processos, estabelecer procedimentos de notificação, feedback ${ }^{(3,6)}$, comunicação e envolvimento do paciente no cuidado $^{(7)}$.

Assim, é necessário que os erros de medicação sejam reportados para se intervir em caráter educativo, preventivo e não punitivo ${ }^{(8)}$. Também para que se amplie o uso de ferramentas de gestão de risco para análise e auxílio na tomada de decisão estratégica, tática e operacional em busca de mais êxito $^{(9)}$.

Contudo, os autores deste artigo perceberam superficialmente nos respectivos serviços que muitas falhas ocorriam durante o processo. Entre elas, que o incidente nem sempre causava prejuízo; muitas vezes não era feita a notificação; comumente havia medo de punição, entre outros.

O National Center for Health Statistics, nos Estados Unidos da América (EUA), em 1997, mostrou que 44.000 pacientes morreram por causa de eventos adversos ${ }^{(10)}$. Estudo realizado em 36 hospitais americanos apontou os erros mais frequentes com medicamentos sendo: horário errado (43\%), omissão (30\%), dose errada (17\%) e aplicação de medicamento sem autorização $(4 \%)^{(11)}$.

Diante deste panorama, questiona-se: Quais os sentimentos experimentados pela equipe de enfermagem frente ao evento adverso medicamentoso e quais barreiras são utilizadas pela enfermagem para prevenção?

Assim, o objetivo deste estudo foi conhecer os sentimentos experimentados pela equipe de enfermagem acerca dos erros de medicação e quais as estratégias foram utilizadas pelos profissionais para preveni-los.

\section{- MÉTODO}

Trata-se de uma pesquisa exploratória e de abordagem qualitativa. Estudiosos aplicam no estudo das relações, representações, crenças, percepções, opiniões, e como os seres humanos percebem a si mesmos e como pensam ${ }^{(12)}$. O local de estudo foi um hospital particular de médio porte, localizado em uma cidade do Sul de Minas Gerais, acreditado em Nível 1 pela Organização Nacional de Acreditação $(\mathrm{ONA})^{(13)}$. 
Os sujeitos foram profissionais de enfermagem das clínicas médica, cirúrgica e pronto socorro, pois participam mais diretamente do processo medicamentoso. A população foi escolhida por conveniência e teve como critérios de inclusão: ser funcionário há mais de seis meses, estar presente no momento da entrevista, ter disponibilidade e aceitar participar da pesquisa. Previamente foi realizado contato com a enfermeira responsável técnica e autorização do hospital, quando foram agendados os dias para coleta dos dados, que ocorreu entre os dias 6 e 17 de outubro de 2014, às sete horas da manhã logo após o momento da troca de plantão. Foram apresentados os objetivos do estudo e garantido o anonimato.

Os dados foram coletados por meio de entrevistas semiestruturadas gravadas, realizadas no local de trabalho em ambiente privativo. A definição do número de participantes foi estabelecida ao longo da coleta pelo critério de saturação de dados(12), e desta forma a amostra se constituiu de 11 profissionais, sendo três enfermeiros e oito técnicos que assinaram o Termo de Consentimento Livre e Esclarecido.

Utilizou-se um roteiro composto por duas partes, sendo a primeira caracterizada pelo perfil dos sujeitos, e a segunda, dados sobre a temática. As entrevistas duraram em média 15 minutos.

Na análise relativa à caracterização dos sujeitos, foi utilizada a estatística descritiva. Após a transcrição na íntegra do conteúdo, os dados qualitativos foram submetidos à análise temática, seguindo as etapas de pré-análise, exploração do material, tratamento dos dados e interpretação ${ }^{(12)}$. As unidades de significado levaram à identificação de categorias e subcategorias, que permitiram a compreensão do fenômeno em estudo.

O referencial teórico utilizado para discussão baseou-se no Protocolo de Londres. Este protocolo recomenda que se faça uma análise do sistema para investigação de incidentes. Sugere que deve ser considerando para a avaliação desde a alta administração até os profissionais diretamente inseridos no processo assistencial, porque há o entendimento que existe uma correlação direta entre o modo como as pessoas se comunicam e se relacionam e a cultura de segurança. O protocolo destaca a importância de se identificar as falhas ativas, consideradas atos inseguros ou omissões feitas pelos profissionais, quer seja lapsos, deslizes e, muito raramente, erros intencionais. E, identificar os fatores contribuintes que representam os aspectos que influenciam a prática cuidativa que vão além do erro humano, por exemplo: saúde física e mental do profissional, fatores tecnológicos, condições psicológicas do paciente, limitações financeiras da instituição, velocidade das decisões gerenciais, entre outros. Sobre isso, sugerem seu uso como um roteiro de investigação, ou seja, que a análise do incidente siga uma abordagem sistemática e estruturada, com intuito de ampliar as oportunidades de progresso ${ }^{(14)}$.

Os sujeitos foram codificados pela letra (E) quando enfermeiros e (T) para técnicos de enfermagem, seguido pelo número da entrevista apontando as respectivas falas. O projeto teve a aprovação do Comitê de Ética e Pesquisa sob o parecer nº 652.430/2014.

\section{- RESULTADOS}

A amostra se constituiu de 11 sujeitos, sendo três (27,27\%) enfermeiros e oito $(72,72 \%)$ técnicos de enfermagem. Quanto ao gênero, somente um (9,09\%) era sexo masculino e dez (90,91\%) feminino. A faixa etária variou de 20 a 40 anos. Quanto ao tempo de exercício profissional, cinco sujeitos (45,45\%) tinham de cinco a dez anos; três $(27,27 \%)$ de dois a cinco anos; dois $(18,18 \%)$ mais de dez anos; e somente um $(9,09 \%)$ tinha menos de um ano de atuação na enfermagem. Quanto ao número de pacientes sob seus cuidados, seis sujeitos (54,54\%) cuidavam de dois a cinco pacientes, e cinco profissionais (45, 45\%) tinham mais de dez pacientes sob seus cuidados.

A exploração e interpretação dos conteúdos possibilitaram a identificação de unidades de significado e o encontro de quatro categorias principais de compreensão: 1) Deficiência na conceituação do erro, 2) Sentimentos negativos associados ao erro, 3) Condutas adotadas perante o erro de medicação, e 4) Estratégias de prevenção contra os erros de medicação.

Os depoimentos direcionados à categoria 1) Deficiência na conceituação do erro geraram duas subcategorias: 1a) Exemplos como forma para apresentar o conceito erro de medicação, e 1b) Erro de medicação como sinônimo de dano. 
Os sujeitos exemplificam uma situação em que acreditam ter ocorrido o erro para conceituá-lo, como relata E-07 para a sub-categoria 1a:

O erro de medicação ele consiste desde o seu aprazamento que é os horários que a gente coloca na prescrição, até a sua administração, então a gente considera como erro de medicação o horário, que se for aprazado errado é considerado um erro de medicação (E-07).

Observa-se a seguir, para a sub-categoria 1b, a conceituação de erro como sinônimo de um dano ocorrido ao paciente, nas falas de E-07, E-11 e T-05 ilustradas:

Todas as profissões podem errar, a nossa é a única que a gente não pode errar que a gente mata um paciente, né? (E-07)

Erro de medicação, toda aquela medicação que é feita ao paciente, que leve um dano pra ele quando é feito de maneira errada, que pode em vez de vir a melhorar as condições dele vem a prejudicar. (E-11)

Erro é quando atrasamos a medicação muito tempo[...]por causa de outros serviços e a gente não pode fazer nada [...] ou faz a medicação em lugar errado [...]. (T-05)

Na categoria 2, sentimentos negativos associados ao erro, quando perguntados aos sujeitos sobre os sentimentos vivenciados na ocasião, destacou-se o medo como o mais forte expresso pelos participantes. A seguir, T-04 e T-10 expressam tal sentimento:

Sentimento de medo, mesmo não sendo comigo, com meus companheiros, mas eu fiquei com medo [...]. (T-04)

Ah foi mais um sentimento de medo, de que poderia ter uma consequência grave. (T-10)

Frente ao episódio do erro, sentimentos de impotência, incapacidade e preocupação foram explicitados em conjunto pelos profissionais que vivenciaram o erro de medicação.

[...] A gente tem sentimento de impotência mesmo né?! (T-02)

Isso é tão triste e deixa a gente pra baixo, não sabe o que fazer, é um sentimento ruim. Faz tudo certo e de repente algo errado acontece. Nem é justo porque às vezes é muito trabalho [...]. Dá muito medo e preocupação porque são várias consequências, pra gente, para o paciente. E se errar de novo, e aí! [...] (T-09)

Sentimentos de preocupação e responsabilidade também são relatados por E-08:

[...] Eu senti responsável junto com ele, então o peso do erro de medicação foi em cima de mim e aí eu fiquei muito preocupada e eu senti esse peso de ter errado, só que o técnico que às vezes tava comigo, ele não tinha conhecimento pra esse peso do erro de medicação, então assim, eu senti essa responsabilidade minha do erro. (E-08)

A realização da conferência do medicamento várias vezes é uma das ações emanadas do sentimento de medo. Tal como aponta o sujeito T-01 a seguir:

[...] mesmo eu sabendo que é aquela medicação, eu confirmo com um, até com dois, eu quero ter certeza realmente porque eu sei que tô lidando com vida né? E eu tenho que prestar muita atenção pra não errar. Então eu prefiro até ser chato às vezes [...]. (T-01)

A categoria 3 evidencia as condutas adotadas pelos sujeitos perante o erro de medicação.

Os profissionais que trabalham nesta instituição são instruídos para comunicar o incidente ocorrido aos supervisores, como relata as falas de T-03 e T-10:

[...] Eu já errei, eu já cometi, eu vi meu erro em seguida, uma, pulando uma dos nove certos comuniquei o enfermeiro que eu tinha errado, a gente comunicou o médico, ficamos observando o paciente, não aconteceu nada. (T-03)

Olha, eu não me lembro nesse tempo de ter acontecido isso, [...] primeira coisa comunicaria o supervisor que é a orientação que a gente tem aqui. (T-10) 
As estratégias de prevenção de erros de medicação, como quarta categoria identificada, sinaliza ações prudentes no contexto do processo de trabalho da enfermagem e da farmácia.

Para o gerenciamento dos riscos contra erros e incidentes nos procedimentos com medicamentos, uma série de conferências preventivas são consideradas essenciais, como a checagem dos cinco certos, dos nove certos e da dupla checagem pela equipe de enfermagem, conforme explicitam as falas:

[...] conferir várias vezes antes; eu sempre quando vou fazer, por exemplo, uma medicação, eu vou antes de aspirar leio o medicamento, depois que aspirei leio de novo e geralmente eu guardo aquela ampola até o momento da administração. (E-11)

[...] É e a gente seguir os nove certos, que se você seguir os nove certos você não vai errar e nós temos os nove certos que é: paciente certo, horário certo, medicação certa, data de validade certa, rótulo, pulseira de identificação beira leito, então é só a gente seguir todos esses passos que aqui a empresa dá esses passos, dificilmente há um erro. (T-01)

[...] Os nove certos né, eu preparo a medicação com a prescrição na mão e confiro também a hora que estou indo pro quarto se é aquela medicação mesmo que eu tô administrando naquele paciente e eu também medico um paciente por vez. [...]. (T-02)

[...] que o funcionário apraza a medicação, os horários de medicação, o enfermeiro checa, vem outro técnico checa novamente, então existe uma dupla checagem em cada plantão né? [...]. (E-07)

Nos depoimentos, a farmácia, ou seja, a central de abastecimento farmacêutico (CAF) é uma unidade responsável por receber, armazenar e dispensar materiais e medicamentos para uso em todo hospital como estratégia ou barreira preventiva, tal como expressam os profissionais:

E eu acho que a conferência na farmácia é o mais importante também, porque se a pessoa conferir a medicação certinha, a chance de ela vir pro setor, pra chegar na mão, ser administrada é menor porque se você barrar o erro é lá entendeu, ela nem sobe. (T-01)

Ah, eu acho que o CAF, lá na farmácia ajuda muito na prevenção, é uma barreira pois há conferência de tudo, antes da medicação sair de lá. (T-06)

\section{DISCUSSÃO}

A identificação das unidades de significado encontrou quatro categorias principais: 1) Deficiência na conceituação do erro, que gerou duas sub-categorias 1a) Exemplos como forma para apresentar o conceito erro de medicação e 1b) Erro de medicação como sinônimo de dano; 2) Sentimentos negativos associados ao erro; 3) Condutas adotadas perante o erro de medicação; e 4) Estratégias de prevenção contra os erros de medicação.

\section{Deficiência na conceituação do erro}

Percebeu-se que os profissionais entrevistados não possuem conhecimento sobre o conceito estabelecido para erro de medicação. Erro de medicação é qualquer evento evitável, causado pelo uso ou aplicação inadequada do medicamento, que pode gerar dano ou prejudicar o paciente. Estes podem estar relacionados à prescrição, dispensação, preparo, administração, entre outros processos ${ }^{(2)}$.

Um estudo com trabalhadores de enfermagem(15) encontrou resultados semelhantes a essa pesquisa. Naquele estudo, nenhum dos profissionais estudados possuía conhecimento na definição preconizada pelo National Coordinating Council for Medication Error Reporting and Prevention ${ }^{(16)}$, entretanto, apresentaram definições lógicas e relevantes acerca do motivo da ocorrência dos erros, apontando subsídios para a possibilidade de aperfeiçoar a educação e consequentemente colaborar com a minimização dos eventos.

Percebeu-se que os entrevistados associam o conceito de erro diretamente com o dano. Dano é definido como um comprometimento da estrutura ou função do corpo e ou qualquer efeito dele 
oriundo, incluindo-se doenças (não decorrentes e/ou previstas), lesão, sofrimento, morte, incapacidade ou disfunção, podendo assim ser prejuízo físico, social ou psicológico ${ }^{(6)}$.

Já o termo evento adverso também se refere a um incidente prevenível e inesperado, que resulta em dano à saúde(6). Percebe-se que há uma correlação e um uso habitual entre os conceitos trazido pela literatura e os verbalizados pelos sujeitos. Nota-se que a terminologia relativa a erro em serviços de saúde no mundo está longe de ser definida. Entretanto, estudiosos afirmam que "precisa-se compreender a definição de erro no contexto da segurança do paciente, pelos protocolos compartilhados em comum, pelas ações de controles, soluções e problemas" ${ }^{\prime \prime 14: 5)}$.

Comentam ainda que a intenção e erro são inseparáveis, ou seja, o termo erro só pode ser aplicado as ações intencionais, caracterizadas pelas falhas na execução e falhas no planejamento ${ }^{(10)}$. Além disso, este se complementa e integra a área jurídica, no qual o erro é advindo de negligência, imprudência e imperícia ${ }^{(3,10)}$.

Sobre o termo evento, a taxonomia da Aliança Mundial da Saúde diz ser "algo que acontece ou que envolve o paciente" causando-lhe dano ${ }^{(17)}$. Este conceito é ampliado para o serviço de saúde, a despeito de que o evento pode causar dano patrimonial, ético e ou moral, e que abrange a instituição, o profissional, o usuário e/ou o meio ambiente ${ }^{(3)}$.

\section{Sentimentos negativos associados ao erro}

Os sujeitos relataram sentimentos negativos experimentados acerca do erro de medicação como: medo, incapacidade, impotência, preocupação e responsabilidade.

O medo, na maioria das vezes, é uma reação adaptativa, servindo a um propósito legítimo e útil de proteger os indivíduos em situações potencialmente perigosas ${ }^{(18)}$. É considerado um instrumento de controle social nas instituições, ainda que possa ser uma verdadeira alavanca para o desempenho na saúde $^{(19)}$.

Neste aspecto, destaca-se o modelo organizacional causal de acidentes e a estrutura dos fatores contribuintes, no qual o Protocolo de Londres explicita que as pessoas são influenciadas pelo ambiente de trabalho, tanto no plano físico quanto nos fatores que afetam a moral e a forma eficaz de trabalhar ${ }^{(14)}$.

Embora às vezes seja fácil identificar uma determinada ação ou omissão como o agente contíguo de um incidente, uma análise mais aprofundada, estruturada e sistemática identificando as falhas ativas e os fatores contribuintes, revela geralmente vários itens dos episódios que induziram ao evento adverso $^{(3)}$.

O sentimento de culpa, o medo da punição, da demissão, e as preocupações com a gravidade do erro podem levar os indivíduos a subnotificarem o incidente. Para mudar esta situação, é relevante a educação dos profissionais por meio de cursos, reciclagem e treinamentos ${ }^{(4)}$, com estudos de cases e cenários realísticos ${ }^{(3)}$.

Quando a análise do incidente é realizada de maneira coerente, as pessoas entrevistadas tendem a considerar o processo menos ameaçador do que a checagem tradicional. O método estruturado destina-se a promover maior clima de abertura, evita a atribuição de culpa e dedos apontados ${ }^{(14)}$ e alivia o sentimento de medo e de punição.

Para aprimorar a segurança do paciente, é preciso, além de estar vigilante às evidências e consensos científicos, ter a competência de entender as especificidades da instituição, do serviço, analisar o cenário de trabalho, os fatores da equipe, o clima organizacional, a complexidade da tarefa, entre outros, no intuito de enfatizar sugestões práticas e sinalizar comportamentos a serem evitados.

O medo, sendo o sentimento mais contundente expresso, é associado diretamente ao receio de não causar mal ao paciente e ou não se prejudicar na carreira profissional. Neste contexto, trata-se do medo de não causar mal ao próximo, e não do medo de punição ou demissão, o que se pode justificar pela forte cultura de segurança que a instituição vivencia.

A promoção da cultura de segurança é disseminada com ênfase no aprendizado e aprimoramento 
organizacional, engajamento dos profissionais e dos pacientes na prevenção de incidentes, com destaque em sistemas seguros, evitando-se os processos de responsabilização individual(3,9-10). Esta e outras estratégias incorporam o Programa Nacional de Segurança do Paciente ${ }^{(6)}$.

Os demais sentimentos negativos relacionados ao erro justificam-se porque, para esses profissionais, cometer engano é inaceitável. Percebe-se aqui os profissionais culpando a si mesmos, deixando de lado a visão de que o sistema pode colaborar para a ocorrência do erro. Como são considerados os instrumentos de busca à saúde e manutenção da vida pelos usuários, acreditam que não podem falhar, mesmo cientes da vulnerabilidade humana ${ }^{(5,10)}$.

Percebeu-se que os sentimentos declarados pelos profissionais envolvidos no erro geram reflexões por ser algo evitável e passível de prevenção.

Na vigência de um evento, a impotência e a culpa tendem a se acentuar, uma vez que a ocorrência implica em risco adicional, inesperado e indesejável ao paciente. E ainda, trata-se de um episódio visto como (des)cuidado, pois traz prejuízos. Estudos evidenciam a preocupação como uma das maiores causas de estresse da equipe de enfermagem, sendo desencadeada pelo intenso conflito de achar que deveria e poderia ter feito alguma coisa que não foi feita ${ }^{(20)}$.

A responsabilidade declarada pelo sujeito T-08 na categoria 2, pode ser entendida como um sentimento que acomete principalmente os enfermeiros supervisores, pelo fato de se sentirem responsáveis por erros cometidos pela sua equipe, sob supervisão. Nota-se que nas ações legais jurídicas, o corresponsável é chamando a lide para dar seu depoimento ao juiz ${ }^{(3)}$, ou seja, tanto no campo emocional quanto processual evidenciam-se sérias questões que entrelaçam a competência e a responsabilidade.

A valorização dos sentimentos abre amplo espaço para que vínculos mais afetivos possam se estabelecer entre os profissionais e a instituição, refletindo assim maior segurança e respaldo ${ }^{(5,10,21)}$.

\section{Condutas adotadas perante o erro de medicação}

Analisou-se que, logo após ocorrência do erro, os indivíduos fortaleceram as atitudes estratégicas para minimizá-los, realizando a conferência do medicamento várias vezes, o que é característico do sentimento de medo, que o protege da recidiva.

Os hospitais não devem negligenciar o erro, mas transformá-lo em motivo para planejar estratégias preventivas e fomentar a adoção da cultura de transparência, com a criação de políticas que estimulem a comunicação dos erros ${ }^{(20)}$, direcionando o plano de ações para a tomada de decisões e das atitudes frente aos mesmos, auxiliando-os na resolução mais assertiva e com menos prejuízos.

Estudo realizado mostrou que a maioria dos profissionais entrevistados compartilhou o evento com outro colega em busca de ajuda nas decisões a serem retomadas e como forma de amenizar os sentimentos desagradáveis que surgem após o acontecimento ${ }^{(22)}$. Um dos melhores meios de obtenção de informações de funcionários e pessoas envolvidas em eventos é por meio de entrevistas, que estão no cerne de uma análise eficaz. Esta deve ocorrer o mais cedo possível, sendo poderosas para explorar sistematicamente os fatores contribuintes ${ }^{(14)}$ e permite a colaboração efetiva dos profissionais no processo de feedback e resolução dos riscos.

Percebeu-se que diante das situações em que o erro de medicação foi constatado, os profissionais de enfermagem estavam preparados, pois sabiam quais condutas iriam seguir. Entre elas, a instrução de comunicar o incidente ao supervisor enfermeiro. Utilizaram da competência comunicação para tal devido à cultura de segurança implantada nesta instituição e reforçada pela conquista do certificado de qualidade do Nível 1 pela Organização Nacional de Acreditação.

\section{Estratégias de prevenção contra os erros de medicação}

Em relação às barreiras utilizadas na prevenção dos erros de medicação, os profissionais relataram como principais métodos utilizados: a conferência simples de medicação, os nove certos, a dupla 
checagem na administração de medicamentos e a central de abastecimento farmacêutico, denominada de CAF pelos profissionais do hospital.

Por conferência simples, entende-se o ato de conferir o nome, embalagem, dose e concentração do medicamento, se são os mesmos da prescrição, além de conferir novamente após o preparo e antes da administração.

Uma administração segura ocorre quando o profissional concentra-se na atividade e antes de administrar, certifica-se de várias formas, recorrendo ao paciente, ao familiar, à identificação no leito ou à pulseira de identificação, as várias barreiras preconizadas ${ }^{(22)}$.

Consideram-se nove certos para administração de medicamentos: paciente certo, medicamento certo, via certa, hora certa, dose certa, registro certo, ação certa, forma certa e resposta certa. Os nove certos não garantem que os erros não ocorrerão, mas seguir barreiras pode prevenir significativamenteos eventos, melhorando o processo de uso seguro dos medicamentos ${ }^{(23)}$. Os participantes relataram que a instituição preconiza, recomenda e disponibiliza a realização dos nove passos nos locais de preparo da medicação, o que tende a evitar esquecimentos e falhas.

A dupla checagem foi outra estratégia expressa pelos sujeitos e consiste no acompanhamento por duas pessoas no processo de preparo, administração e checagem de medicações de modo independente e simultâneo ${ }^{(24)}$.

O procedimento de dupla checagem na administração de medicamentos é também padronizado pela instituição de estudo como barreira de prevenção. No entanto, nem sempre é possível realizálo devido a intercorrências diárias como excesso de demanda, recursos humanos quantitativamente limitados, emergências e ou sobrecarga de tarefas. Por isso, o enfermeiro deve monitorar o sistema, agir e interceptar qualquer falha precocemente.

A CAF recebe, armazena e dispensa materiais e medicamentos no hospital, e é apontada pelos sujeitos como uma barreira preventiva para erros e danos. Observa-se que a instituição possivelmente está conforme frente ao protocolo do Ministério da Saúde, que designa à CAF práticas adequadas e seguras para evitar incidentes e erros na guarda e distribuição de medicamentos ${ }^{(24)}$.

Destarte, é necessário que a política de segurança definida pela instituição reforce a conduta de não punição do profissional(15,25); utilize os casos de erro de medicação em cases para capacitação coletiva; dissemine as condutas assertivas ${ }^{(3)}$; alimente a gestão de riscos com atitudes preventivas; oportunize a comunicação ativa de ideias e inovações efetivamente; e promova o ambiente para notificação de evento adverso, sem medo na instituição.

\section{CONSIDERAÇÕES FINAIS}

O estudo permitiu conhecer os sentimentos experimentados pelos profissionais de enfermagem e as deficiências no conceito de erro. Percebeu-se que os sujeitos exemplificam o erro e não o conceituam. O medo aparece nos discursos, porém não relacionado à punição, mas como consequência de prejuízos para o paciente. A responsabilidade e a comunicação foram competências de conduta usadas pelos sujeitos diante do erro de medicação.

Nota-se a limitação do estudo no que tange à determinação do horário para coleta de dados, o que impossibilitou a participação de profissionais do turno da tarde. Nova pesquisa está sendo realizada para ampliar esta temática na instituição.

Os sujeitos utilizam algumas estratégias preconizadas por órgãos oficiais e barreiras estabelecidas no serviço, para minimizar o erro demonstrado. Sugere-se a implantação da sensibilização ou educação contínua, com foco em segurança, como meio para alcançar maior conhecimento sobre o conceito de erro, dano e outros aspectos inerentes à prevenção de riscos e a cultura de segurança institucional.

Almeja-se que esta pesquisa contribua no desenvolvimento de medidas preventivas ante os erros de medicação e que gere subsídios para implementação de ações e aprendizado no que tange ao alívio dos sentimentos dos envolvidos e fortalecimento das condutas assertivas pelos profissionais de saúde. 
1. Conselho Regional de Enfermagem de São Paulo. Casos Stephanie e Mariana: onde cabe o direito e o dever. Revista Enfermagem. [Internet] 2010; 11(87) [acesso em 11 nov 2015]. Disponível:

http://www.coren-sp.gov.br/sites/default/files/revista_enfermagem_dezembro_2010_0.pdf.

2. National Coordinating Council for Medication Error Reporting and Prevention (NCC MERP). NCC MERP Taxonomy of medication errors. [Internet] 2001 [acesso em 11 nov 2015]. Disponível:

http://www.nccmerp.org/sites/default/files/taxonomy2001-07-31.pdf.

3. Feldman LB, organizadora. Gestão de risco e segurança hospitalar: prevenção de danos ao paciente, notificação, auditoria de risco, aplicabilidade de ferramentas, monitoramento. São Paulo: Martinari; 2008.

4. Silva AEBC, Cassiani SHB. Errors of medication in a University Hospital: type, causes, suggestions and actions. Rev. bras. enferm. [Internet] 2004; 57(6) [acesso em 08 jun 2016]. Disponível:

http://dx.doi.org/10.1590/S0034-71672004000600007.

5. Franco JN, Ribeiro G, D'Innocenzo M, Barros BPA. Percepção da equipe de enfermagem sobre fatores causais de erros na administração de medicamentos. Rev. bras. enferm. [Internet] 2010; 63(6) [acesso em 20 jun 2016]. Disponível: http://dx.doi.org/10.1590/S0034-71672010000600009.

6. Ministério da Saúde (BR). Portaria n. 529, de 01 de abril de 2013. Institui o Programa Nacional de Segurança do Paciente (PNSP). Diário Oficial da União, [Internet] 02 abr 2013 [acesso em 11 nov 2015]. Disponível: http://www. jusbrasil.com.br/diarios/52582397/dou-secao-1-02-04-2013-pg-43.

7. Associação Brasileira de Normas Técnicas (ABNT). NBR ISO 31000: Gestão de riscos: princípios e diretrizes [Internet]. Rio de Janeiro: ABNT; 2009 [acesso em 11 nov 2015]. Disponível:

http://www.totalqualidade.com.br/2010/06/abnt-nbr-iso-31000-principios-da-gestao.html.

8. Corbellini VL, Schilling MCL, Frantz SF, Godinho TG, Urbanetto JS. Medication-related adverse events: perception of nursing aides. Rev. bras. enferm. [Internet] 2011; 64(2) [acesso em 08 jun 2016]. Disponível:

http://dx.doi.org/10.1590/S0034-71672011000200004.

9. Shimabukuro PM, Paulon P, Feldman LB. Implementation of bundles in intensive care unit: an experience report. Rev. enferm. UFSM. [Internet] 2014; 4(1) [acesso em 11 nov 2015]. Disponível:

http://cascavel.ufsm.br/revistas/ojs-2.2.2/index.php/reufsm/article/view/11097/pdf.

10. Kohn LT, Corrigan JM, Donaldson MS, editors. To err is human: building a safer health system. [Internet] Washington (DC): National Academy Press; 2000 [acesso em 11 nov 2015]. Disponível:

http://www.nap.edu/read/9728/chapter/1.

11. Barker KN, Flynn EA, Pepper GA, Bates DW, Mikeal RL. Medication errors observed in 36 health care facilities. Arch Intern Med. 2002; 162(16): 1897-903.

12. Minayo MC. O desafio do conhecimento: pesquisa qualitativa em saúde. 12a ed. São Paulo: Hucitec; 2010.

13. Organização Nacional de Acreditação (ONA). Manual Brasileiro de Acreditação: Organizações Prestadoras de Serviços de Saúde. São Paulo: ONA; 2014.

14. Vincent C, Burnett S, Carthey J, organizadores. The measurement and monitoring of safety: Drawing together academic evidence and practical experience to produce a framework for safety measurement and monitoring. [Internet] London: Health Foundation; 2013 [acesso em 11 nov 2015]. Disponível:

http://www.health.org.uk/sites/default/files/TheMeasurementAndMonitoringOfSafety_fullversion.pdf.

15. Telles Filho PCP, Praxedes MFS, Pinheiro MLP. Measurement errors: analysis of the nursing staff's knowledge in a hospital. Rev. Gaúcha Enferm. [Internet] 2011; 32(3) [acesso em 08 jun 2016]. Disponível: http://dx.doi.org/10.1590/S1983-14472011000300015

16. National Patient Safety Foundation (NPSF). Patient safety dictionary A-E. [Internet] Boston (MA): National Patient Safety Foundation; 2015 [acesso em 11 nov 2015]. Disponível: http://www.npsf.org/?page=dictionaryae. 
17. World Health Organization (WHO). Health topics: hospitals. [Internet] Geneva: World Health Organization; 2015 [acesso em 11 nov 2015]. Disponível: http://www.who.int/topics/hospitals/en/.

18. Schoen TH, Vitalle MSS. What am I afraid of?. Rev. paul. pediatr. [Internet] 2012; 30(1) [acesso em 08 jun 2016 ]. Disponível: http://dx.doi.org/10.1590/S0103-05822012000100011.

19. Sarquis LMM, Felli VEA. The feelings experienced after occupational exposure among health care workers: fulcrum approach to work in health institutions. Rev. bras. enferm. [Internet] 2009; 62(5) [acesso em 08 jun 2016]. Disponível: http://dx.doi.org/10.1590/S0034-71672009000500008.

20. Padilha KG, Kitahara PH, Gonçalves CCS, Sanches ALC. latrogenic events with medications at the intensive care unit: procedures and feelings expressed by nurses. Rev. esc. enferm. USP [Internet] 2002; 36(1) [acesso em 11 nov 2015]. Disponível: http://dx.doi.org/10.1590/S0080-62342002000100008.

21. Bohomol E, Ramos LH. Perceptions about medication errors: analysis of answers by the nursing team. Perceptions about medication errors: analysis of answers by the nursing team. Rev. Latino-Am. Enfermagem. [Internet] 2006; 14(6) [acesso em 08 jun 2016]. Disponível: http://dx.doi.org/10.1590/S0104-11692006000600009.

22. Santos JO, Silva AEBC, Munari DB, Miasso AI. Condutas adotadas por técnicos de enfermagem após ocorrência de erros de medicação. Acta paul. enferm. [Internet] 2010; 23(3) [acesso em 08 jun 2016]. Disponivel: http://dx.doi.org/10.1590/S0103-21002010000300003.

23. Elliott M, Liu Y. The nine rights of medication administration: an overview. Br J Nurs. 2010; 19(5): 300-5.

24. Ministério da Saúde (BR), Agência Nacional de Vigilância Sanitária (ANVISA), Fundação Oswaldo Cruz (FIOCRUZ), Fundação Hospitalar do Estado de Minas Gerais (FHEMIG), coordenadores. Anexo 03: Protocolo de segurança na prescrição, uso e administração de medicamentos. [Internet] 2013 [acesso em 11 nov 2015]. Disponível: $\quad$ http://www20.anvisa.gov.br/segurancadopaciente/index.php/publicacoes/item/seguranca-naprescricao-uso-e-administracao-de-medicamentos.

25. Lameu CA, Corazza E. Estratégias para minimizar o erro na administração de medicamentos. Rev Enferm UNISA. [Internet] 2010; 11(2) [acesso em 14 nov 2015]. Disponível:

http://www.unisa.br/graduacao/biologicas/enfer/revista/arquivos/2010-2-07.pdf. 